\title{
Why we urgently need a public subsidence information service in the Netherlands
}

\author{
Tirza M. van Daalen, Peter A. Fokker, Paul J. F. Bogaard, and Michiel J. van der Meulen \\ Geological Survey of the Netherlands, part of TNO, Utrecht, 3584 CB, the Netherlands \\ Correspondence: Peter A. Fokker (peter.fokker@tno.nl)
}

Published: 22 April 2020

\begin{abstract}
Geological surveys traditionally assess past and present processes in the subsurface, focusing mainly on exploration and extraction of natural resources. Applications like these determined how geological surveys designed and operated their information services. In recent years, information needs are rapidly evolving in conjunction with emerging societal challenges such as climate change and the related energy transition. Both challenges have a geological component and have potentially large implications for future land use. Subsidence is a particularly wicked challenge to the Dutch lowlands. These lands are drained to keep them arable and habitable, while drainage causes subsidence. They overlie hydrocarbon and other geological recourses of which the production causes subsidence too. The effects of both - increased flood risk - are aggravated by climate change and sea-level rise. Managing these risks requires knowing and understanding the connection between subsurface processes and surface movement. This knowledge must be quantitative. Subsidence forecasts can be improved by squeezing all possible information out of a variety of local data, ranging from geological data that bear information on subsidence potential to geodetic data which allow for subsidence monitoring. This paper will substantiate the value of subsidence information for governance in sensitive areas, using examples in The Netherlands. In particular, the potential role of a nation-wide, freely accessible repository for subsidence data will be highlighted.
\end{abstract}

\section{Introduction}

Inhabitants of the Dutch delta have significantly adapted the landscape to make and keep it habitable for well over a 1000 years. These adaptations have large consequences also in the long term. Subsidence is the most significant of these (Erkens et al., 2016).

Over the last 50 years the pressure on the country's liveability has further increased. Reasons include the population increase, climate change and the accompanying sea level rise, and the long history of exploitation of deep geo-resources (oil, gas and salt) that cause further subsidence. Subsidence is traditionally governed with adaptation methods like higher levees or further lowering of groundwater levels. However, in various places, such methods have reached the end of their usability. As an unavoidable consequence, far-reaching measures will be needed in the coming decades to safeguard the habitability of the Netherlands.
Subsidence is a slow and complex phenomenon, because multiple processes are not only causing subsidence but also affect each other. As a result, it is challenging to oversee the long-term consequences of interventions both on the surface and in the subsurface.

\section{Societal questions related to subsidence}

Subsidence is a wide-spread phenomenon in the Netherlands. It is caused in part by natural processes (Kooi et al., 1998), but to a more significant extent by human interventions (Erkens et al., 2016). Examples of such interventions include land reclamation, groundwater management, exploitation of oil, gas, other forms of geo-energy, salt and drinking water, and the development of large infrastructural works. Subsidence has major impacts on infrastructure (roads, railways, bridges and tunnels, dams and levees, subsurface cables and 
pipelines), water management, the built environment, land use and coastal morphology.

Governments and companies are increasingly confronted with questions on how to deal with the consequences of subsidence now and in the future:

- In agricultural areas, should we keep on adapting groundwater levels to land use, or should we adapt land use itself?

- Should we continue to elevate dikes and levees, or should we find other ways to protect ourselves to flooding hazards?

- What are the expected costs for infrastructure maintenance, and how can we keep these costs as low as possible?

- What is the underlying cause of subsidence related damage to houses and other buildings, and who - if anyone - can be held responsible?

- What kind of monitoring is required and at which level? What is the added value?

To answer such questions, knowledge of and information on subsidence and the underlying processes is indispensable. Currently these questions are addressed in local and regional projects (see, e.g. Koster et al., 2018). Subsidence however affects a large number of people and organisations and a national approach is needed.

\section{Management of the Subsidence information cycle}

Management, mitigation or adaptation to subsidence is vital. Decisions, however, can only be faithfully made on the basis of quantitative information. The related information cycle to manage subsidence in all its aspects requires information of various nature:

- Data and monitoring: how much subsidence occurs at which place and with what rate?

- Knowledge of driving processes: what is causing subsidence in the given circumstances?

- Predictive models - i.e. a quantitative description that translates the driving processes and the governance choices in faithful subsidence forecasts.

- Model parameterization: have subsidence data been used to infer parameters in the driving models?

- Interventions and remediation measures including monitoring: what has been done?

As said, the current initiatives to address subsidence are local, and most of the time they focus on a specific challenge. To be able to address the listed societal questions, integrated

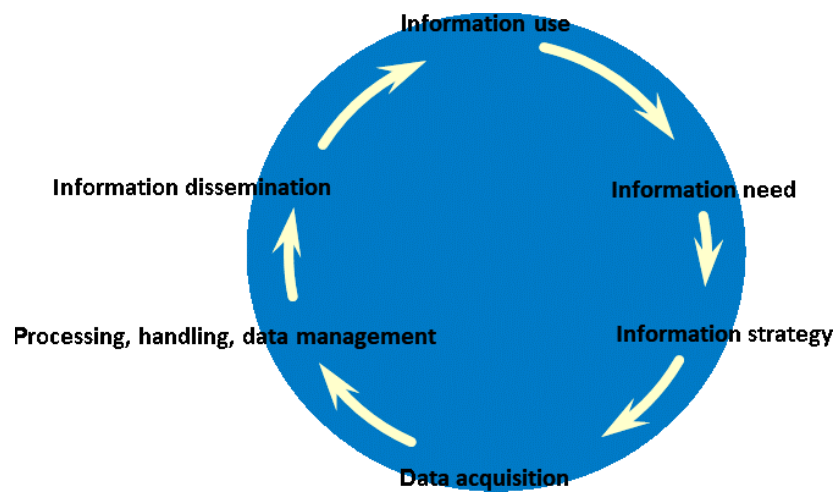

Figure 1. Information cycle for optimum decision making.

data and knowledge is needed. An information cycle is required that ensures unambiguous, reliable, up to date data and information in such a way that it can be used by endusers for different purposes (Fig. 1). A quality description in the data is critical for later use in quantitative models.

The combined requirements just listed are complicated by a number of properties inherent to the phenomenon of subsidence. Firstly, it is a complex problem in which many processes, mechanisms and scales are interacting and must be coupled in comprehensive models. Secondly, there are particular difficulties in measurement procedures and modelling approaches that call for dedicated expert knowledge. Reliable, accurate, transparent, shared data, models and information are required, covering the entire information cycle. And, finally, the continuity of availability of data and models must be preserved.

In our opinion the combined requirements call for a nation-wide, public service. Information must be available on the national level and accessible for all parties in a transparent and open way. This way, regional and local expertise and innovation can be leveraged.

The approach just sketched is at the heart of the work of Geological Survey of the Netherlands (Van der Meulen et al., 2013). Indeed, geological surveys have been designed to build, operate and maintain these information cycles. While their activities were traditionally in the fields of groundwater, resources exploration or geo-engineering, addressing topics as subsidence on a national level will lift the information services to the next level. It introduces a permanent dynamic dimension into the existing portfolio.

\section{Conclusions and discussion}

The objective of a public subsidence Information Service should be to make unambiguous, reliable, up-to-date information on subsidence available in such a way that it can be used by a range of end-users for a range of different purposes. 
The Information Service should define Information Products in close consultation with stakeholders, and should include a quality control system for data and models.

For maintenance of the infrastructure as well as management and disclosure of information, the information service should take advantage of a number of existing initiatives and responsibilities, such as the Key Register of the Subsurface (BRO), and the information services of the Geological Survey of the Netherlands, TNO.

Further innovations will be needed in the coming decennia. Such innovations will help stakeholders in the Netherlands to take well-informed decisions and avoid costs and/or keep them under control. The outreach, however, can be even larger when they are used in other parts of the world. We feel that there are many comparable regions that could benefit from applying similar approaches as we now intend to build for the Netherlands.

Data availability. No data sets were used in this article.

Author contributions. TMvD conceived the idea of this article and wrote the text. PAF, PJFB and MJvdM contributed to the development of the ideas and edited the text.

Competing interests. The authors declare that they have no conflict of interest.
Special issue statement. This article is part of the special issue "TISOLS: the Tenth International Symposium On Land Subsidence - living with subsidence". It is a result of the Tenth International Symposium on Land Subsidence, Delft, the Netherlands, 17-21 May 2021

\section{References}

Erkens, G., Van der Meulen, M., and Middelkoop, H.: Double trouble: Subsidemnce and $\mathrm{CO}_{2}$ respirations due to 1000 years of cultivation of the Dutch coastal peatlands, Hydrogeol. J., 24, 551$568,2016$.

Kooi, H., Johnston, P., Lambeck, K., Smither, C., and Molendijk, R.: Geological causes of recent $(\sim 100 \mathrm{yr})$ vertical land movement in the Netherlands, Tectonophysics, 299, 297-316, 1998.

Koster, K., Stafleu, J., and Stouthamer, E.: Differential subsidence in the urbanised coastal-deltaic plain of the Netherlands, Neth. J. Geosci., 97, 215-227, 2018.

Van der Meulen, M. J., Doornenbal, J. C., Gunnink, J. L., Stafleu, J., Schokker, J., Vernes, R. W., van Geer, F. C., van Gessel, S. F., van Heteren, S., van Leeuwen, R. J. W., Bakker, M. A. J., Bogaard, P. J. F., Busschers, F. S., Griffioen, J., Gruijters, S. H. L. L., Kiden, P., Schroot, B. M., Simmelink, H. J., van Berkel, W. O., van der Krogt, R. A. A., Westerhoff, W. E., and van Daalen, T. M.: 3D geology in a 2D country: perspectives for geological surveying in the Netherlands, Neth. J. Geosci., 92, 217-241, 2013. 